\title{
Influence of the bioreaction on long term operation of a submerged membrane adsorption hybrid system
}

\author{
W. S. Guo ${ }^{a}$, S. Vigneswaran ${ }^{a^{*}}$, H. H. Ngo ${ }^{a}$, T. B. Van Nguyen $^{a}$ \\ and R. Ben Aim ${ }^{\mathrm{b}}$ \\ ${ }^{a}$ Faculty of Engineering, University of Technology, Sydney, \\ PO Box 123, Broadway, NSW 2007, Australia \\ Tel: +61 (2) 95142641, Fax: + 61(2) 95142633, Email: s.vigneswaran@uts.edu.au \\ ${ }^{b}$ LIPE/INSA, Toulouse, France
}

\begin{abstract}
This study is to investigate on the long term performance of submerged membrane adsorption hybrid system (SMAHS) for organic matter removal from synthetic wastewater representative of biologically treated wastewater using low dose of powder activated carbon (PAC). A simple periodic backwash system is used to declog the hollow fiber membrane. In this reactor, bioreaction takes place due to the growth of the biomass in the system. This hybrid system was able to remove effectively the small and large molecular weight organic matters from 270 to 36270 daltons. The effect of PAC replacement in the reactor was also studied and the PAC replacement could enhance both biological activity and adsorption. With PAC replacement of $2.5 \%$ (total amount) per day, the total organic carbon (TOC) removal efficiency was $10 \%$ higher than the one without PAC replacement. In another long term experiment, the TOC removal efficiency was maintained over $85 \%$ even after 55 days operation (with PAC replacement rate of $2.5 \%$ (total amount) every two days).
\end{abstract}

Keywords: Submerged membrane adsorption hybrid system; Biodegradation; Molecular weight distribution

\section{Introduction}

Water reclamation and reuse are considered as an unavoidable stage not only for alleviating the contradiction of growing water demand in connection with limiting water resources, but also for protecting existing water sources being polluted. Nowadays, the use of membrane filtration technology has been an increasing issue in replacing the conventional water and wastewater treatment processes to produce high quality treated water.

\footnotetext{
* Corresponding author
} 
Among the membrane processes, submerged membrane bioreactorsr (SMBR) is regarded as an alternative technology to meet stringent water regulations because of low energy consumption, high efficiency and cost-effective option [1]. However, the membrane fouling is still a major problem. Various attempts have been made to reduce the membrane fouling in submerged MBR. Yamamoto et al. [2] examined the influence of operational modes and found that intermittent suction reduced membrane fouling greatly compared to continuous suction. Lee at al. [3] indicated that alum and natural zeolite addition to a submerged MBR not only reduced membrane fouling, but also increased the removal of COD removal. Furthermore, the association of SMBR and PAC became a promising unit process for advance water treatment, because the addition of PAC as pretreatment to membrane processes (such as MF or UF) could achieve more DOC and DBPs removal and mitigate membrane fouling by reducing organic loading to membrane adsorbing organic matters [4,5]. In submerged membrane adsorption hybrid system (SMAHS), the entire treatment activity (such as adsorption/biodegradation, liquid-solid separation, and sludge accumulation and withdrawal) can be carried out in a single unit.

This combination has been developed for removing organic micropollutants in the production of drinking water (CRISTAL process) [6]. The use of PAC in conjunction with different UF systems has been successfully demonstrated for removal of synthetic organic chemical (3,4,6-trichlorophenol) and NOM at bench scale and at pilot plants [7,8]. Kim et al. [4] used the SMBR hybrid system to remove organics and coliphage $\mathrm{Q} \beta$ strain from synthetic wastewater (TOC $=10 \mathrm{mg} / \mathrm{L}$ ). They found that the organic removal efficiency of the system was consistently more than $95 \%$ with a PAC dose of $40 \mathrm{~g} / \mathrm{L}$ for 40 days. The results indicated that adsorption of organic matter on PAC could reduce the organic fouling. Nevertheless, a high concentration of PAC could result in the formation of a cake at the membrane surface, thus reducing the effectiveness of physical cleaning by aeration and increasing the filtration resistance.

In this study, a SMAHS was investigated to treat a synthetic secondary sewage effluent using a low dose of $5 \mathrm{~g} / \mathrm{L}$ PAC (PAC is added only at eh start of the experiment). In such a reactor, bioreaction took place due to the growth of the biomass supported by PAC. Experiments were conducted for looking at the respective efficiencies of the biodegradation and adsorption.

\section{Experimental}

\subsection{Wastewater}

A series of long-term experiments was conducted using a synthetic wastewater which contains persisting (less biodegradable) organic compounds, such as humic acid, tannic acid, lignin, lauryle, acacia gum powder, polysaccharide, beef extract and peptone. This synthetic wastewater represents the biologically treated sewage effluent [9]. The total organic carbon (TOC) of the synthetic wastewater was between 3.8-4.2 $\mathrm{mg} / \mathrm{L}$ and COD was $60-65 \mathrm{mg} / \mathrm{L}$.

\subsection{SMAHS set-up}


A hollow fiber membrane module was used and the characteristics of the hollow fiber membrane module are summarized in Table 1. The schematic diagram of the submerged hollow fiber microfiltration system is shown in Figure 1. Synthetic wastewater was pumped into the reactor using a feeding pump to control the feed rate while the effluent flow rate was controlled by a suction pump. Level sensor was used to control the wastewater volume in the reactor. A predetermined amount of PAC was added into the tank to adsorb the dissolved organic substances. The PAC $(80 \% \mathrm{~min}$ finer than 75 micron) used was wood based with surface area of $882 \mathrm{~m}^{2} / \mathrm{g}$ and mean pore diameter $30.61 \AA$. A pressure gauge was used to measure the transmembrane pressure (TMP) and a soaker hose air diffuser was used to maintain a high air flow rate. The bubbling air has three functions in this system: (i) sweeping the membrane surface, (ii) mixing the PAC in SMAHS and (iii) supplying oxygen to facilitate the biological degradation organics on the PAC during the long term operation of SMAHS.

Table 1

Characteristics of the hollow fiber membrane module

\begin{tabular}{lc}
\hline \multicolumn{1}{c}{ Items } & Characteristics \\
\hline Material & Polyethylene with hydrophilic coating \\
Nominal pore size & $0.1 \mu \mathrm{m}$ \\
Outer diameter & $0.41 \mathrm{~mm}$ \\
Inner diameter & $0.27 \mathrm{~mm}$ \\
No. of fiber & $320(16 \times 20)$ \\
Length of fiber & $12 \mathrm{~cm}$ \\
Surface area & $0.05 \mathrm{~m}^{2}$ \\
Membrane packing density & $9858 \mathrm{~m}^{2} / \mathrm{m}^{3}$ \\
Membrane manufacturer & Mitsubishi-Rayon, Tokyo, Japan \\
\hline
\end{tabular}

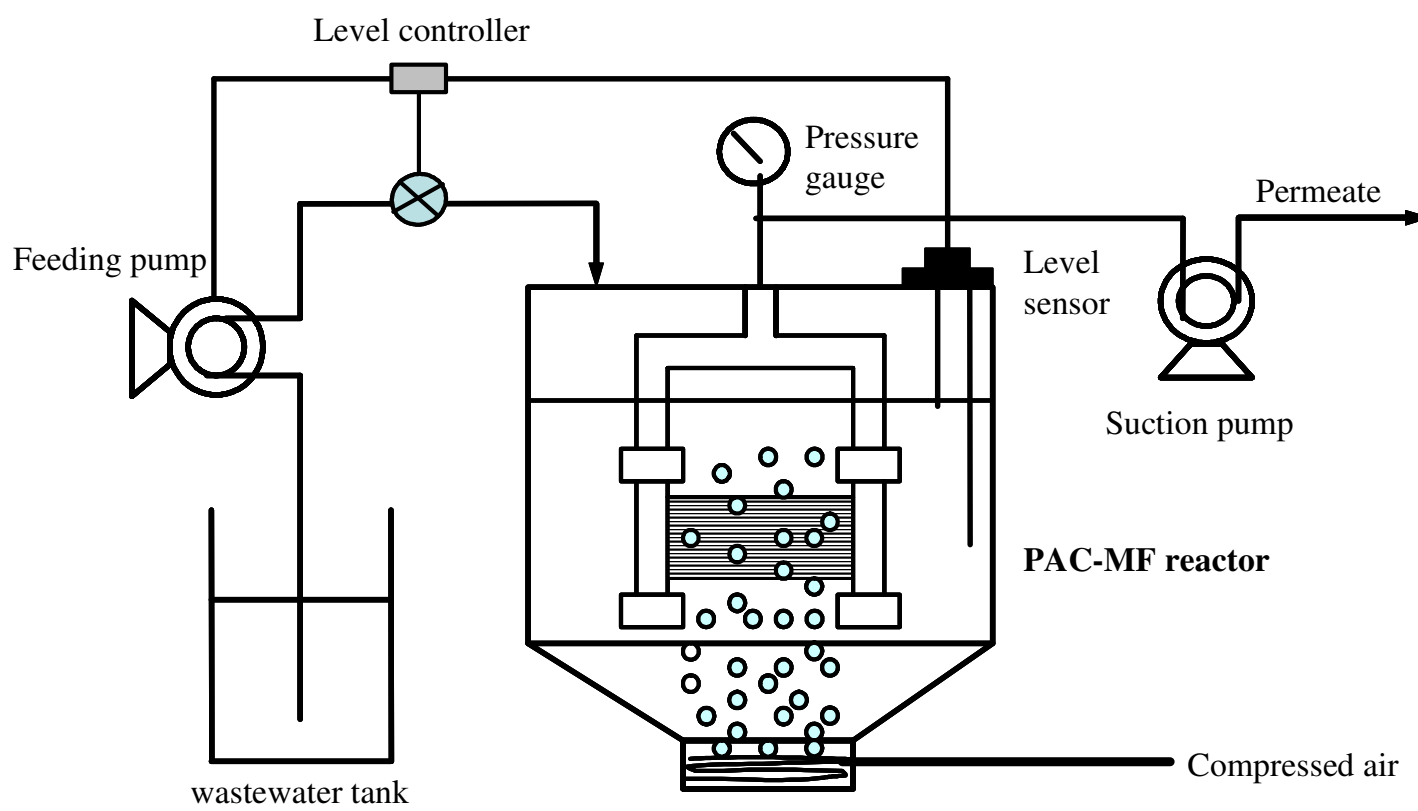

Figure 1 Experimental set-up of SMAHS 


\subsection{Analysis}

Molecular weight (MW) distribution of dissolved organic matter was analysed prior to and after the pretreatment. High pressure size exclusion chromatography (HPSEC, Shimadze, Corp., Japan) with a SEC column (Protein-pak 125, Waters, Milford, USA) was used to determine the MW distributions of organics. The equipment was calibrated using the standards of MW of various polystyrene sulphonates (PSS: 210, 1800, 4600, 8000 and 18000). The MW distribution results were analysed using the response $(\mathrm{mV})$ data of HPSEC with elapsed time. Total organic carbon (TOC) of the influent and effluent was measured using the UV-persulphate TOC analyser (Dohrmann, Phoenix 8000). Dissolved oxygen (DO) variation of the wastewater withdrawn from the aeration tank at different periods was monitored using an oxygen monitor (YSI Model 5300).

\section{Results and Discussion}

\subsection{Long term performance of SMAHS with and without PAC replacement}

A series of 15 days-experiments were carried out to clarify the effect of the effect of PAC replacement and biodegradation using the synthetic secondary sewage effluent. Two conditions of the operation have been compared, one without PAC replacement, and the other with PAC replacement at a constant rate $(2.5 \%$ of total PAC amount per day). In the case of PAC replacement, a $200 \mathrm{ml}$ solution was withdrawn from the reactor on a daily basis and compensated back with a $200 \mathrm{ml}$ influent which contained $1 \mathrm{~g}$ PAC.

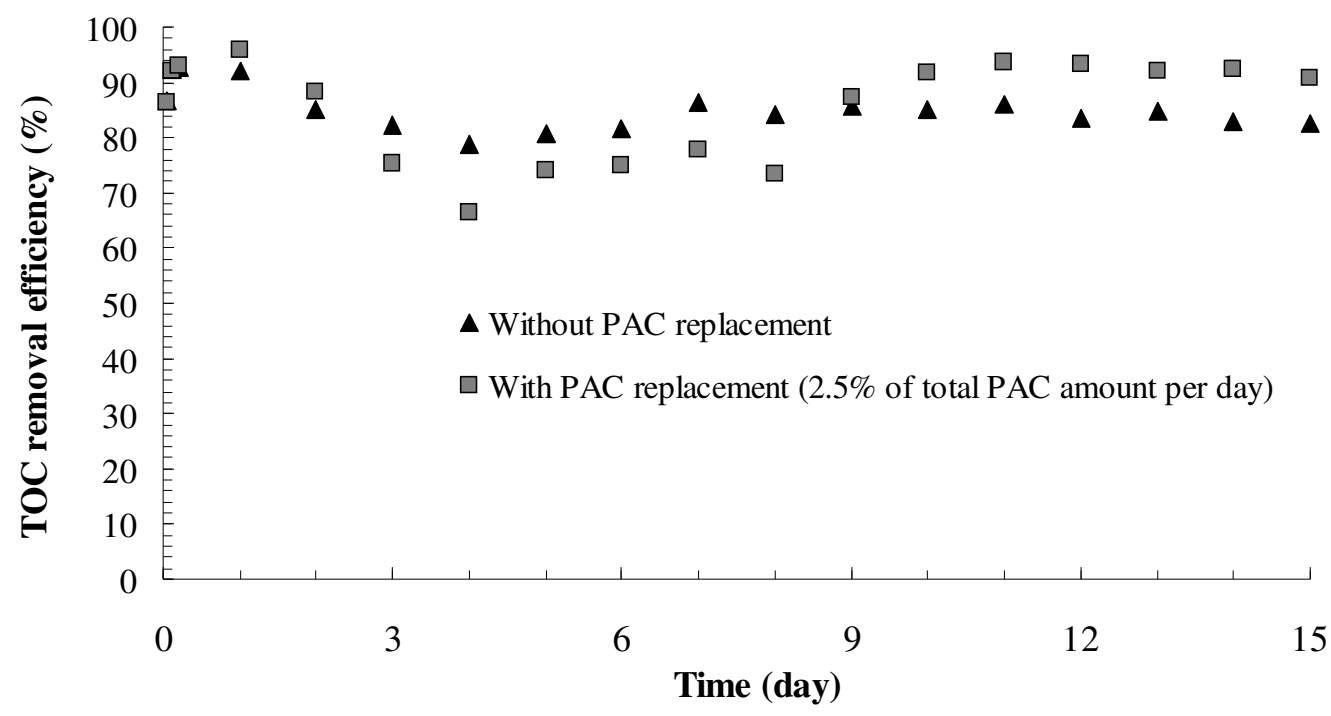

Figure 2 TOC removal efficiency versus operation time (PAC dose $=5 \mathrm{~g} / \mathrm{L}$; filtration rate $=12 \mathrm{~L} / \mathrm{m}^{2} . \mathrm{h}$; aeration rate $=12 \mathrm{~L} / \mathrm{min} ; \mathrm{HRT}=0.56$ day; backwash frequency $=2$ times/day; backwash duration $=2$ minutes; backwash rate $=30 \mathrm{~L} / \mathrm{m}^{2} . \mathrm{h}$ )

Figure 2 shows the variation of the TOC removal efficiency with these two conditions. During the first 9 days, the system without PAC replacement was about 4\% more efficient than the one with PAC replacement. However, after 9 days, the system with 
PAC replacement became more efficient in terms of TOC removal. The TOC removal efficiency was up to $82 \%$ after 15 days run without PAC replacement. However, the PAC replacement enabled to obtain higher TOC removal efficiency $(>90 \%)$ even after 15 day-operation. This phenomenon can be explained by the following two different mechanisms predominant in organic removal in the aerated tank: adsorption and biodegradation (Figure 3). It can be seen that, without replacement, the adsorptive capacity of PAC was saturated after one day of operation. Since the biodegradation behavior was quite limited, the TOC concentration in the aeration tank decreased after 6 days. With PAC replacement, the renewal of PAC limited the growth of TOC concentration in the aeration tank because of the simultaneous activities of biodegradation and adsorption. However, in both conditions of operation (with and without PAC replacement), the quality of the permeate remained good (TOC $<1 \mathrm{mg} / \mathrm{L}$ ).

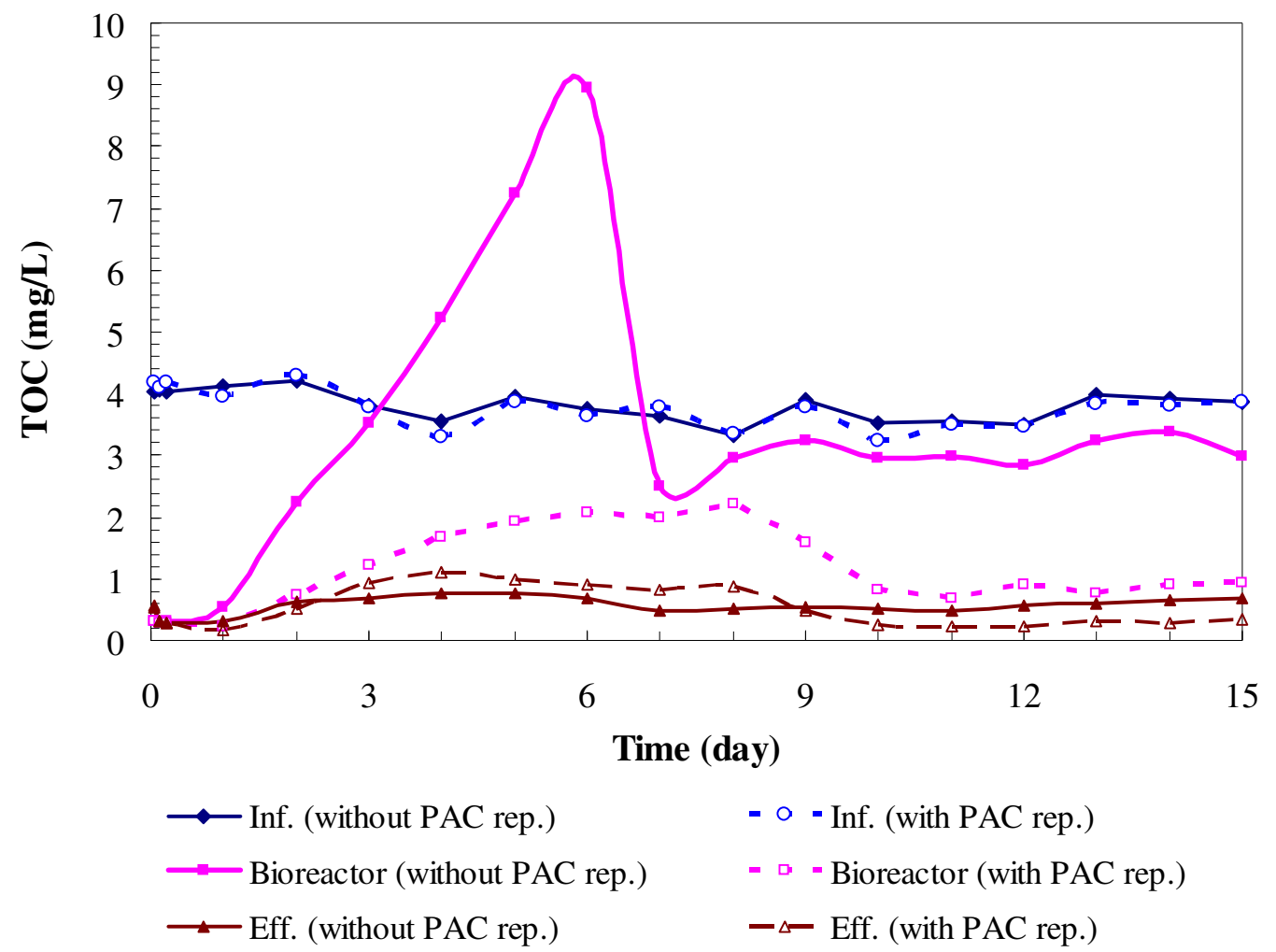

Figure 3 Variation of TOC of influent, PAC-MF reactor and effluent (PAC dose $=5$ $\mathrm{g} / \mathrm{L}$; filtration rate $=12 \mathrm{~L} / \mathrm{m}^{2} . \mathrm{h}$; aeration rate $=12 \mathrm{~L} / \mathrm{min} ; \mathrm{HRT}=0.56$ day; backwash frequency $=2$ times/day; backwash duration $=2$ minutes; backwash rate $=30 \mathrm{~L} / \mathrm{m}^{2} . \mathrm{h}$ )

\subsection{Long term SMAHS experiments with filtration flux of $24 \mathrm{~L}^{2}{ }^{2} . h$}

The experiment was conducted at filtration flux of $24 \mathrm{~L} / \mathrm{m}^{2}$.h with hourly backwash for 1 minute. The PAC dose and PAC replacement rate were $5 \mathrm{~g} / \mathrm{L}$ and $2.5 \%$ total PAC amount each every 2 days respectively. After 15 days run, the SMAHS still led to a high TOC removal efficiency over $80 \%$ with an average TOC removal efficiency of $84.5 \%$ (Figure 4). The TMP during the 15 -day operation increased by $42 \mathrm{kPa}$. The biomass growth in the SMAHS was stable (around $7.4 \mathrm{~g} / \mathrm{L}$ ) after a dramatic increase 
during the first 4 days (Figure 5). Here, the biomass was measured in terms of dry mass.

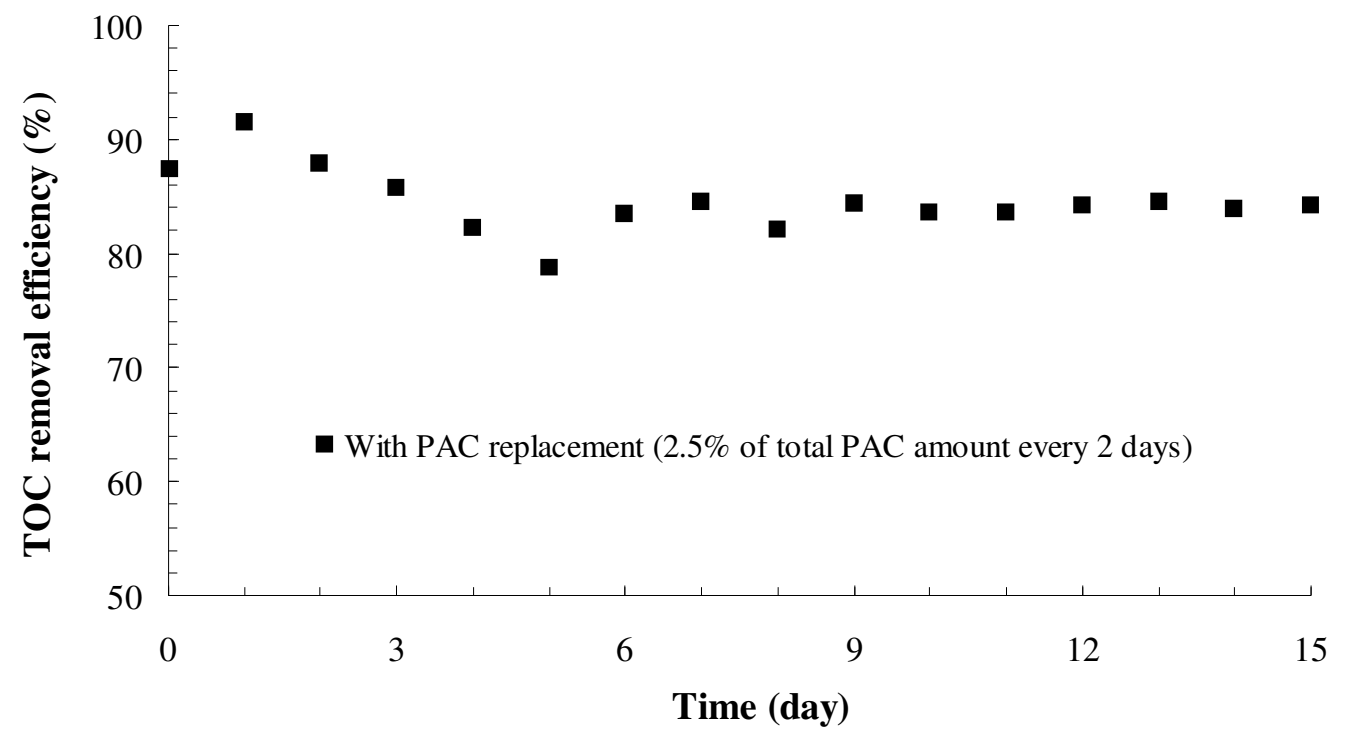

Figure 4 TOC removal efficiency of SMAHS experiment at filtration flux of 24 $\mathrm{L} / \mathrm{m}^{2} . \mathrm{h}(\mathrm{PAC}$ dose $=5 \mathrm{~g} / \mathrm{L}$; aeration rate $=16 \mathrm{~L} / \mathrm{min} ; \mathrm{HRT}=0.21$ day; backwash frequency $=1$ hour; backwash duration $=1$ minute; backwash rate $=30 \mathrm{~L} / \mathrm{m}^{2} . \mathrm{h}$ )

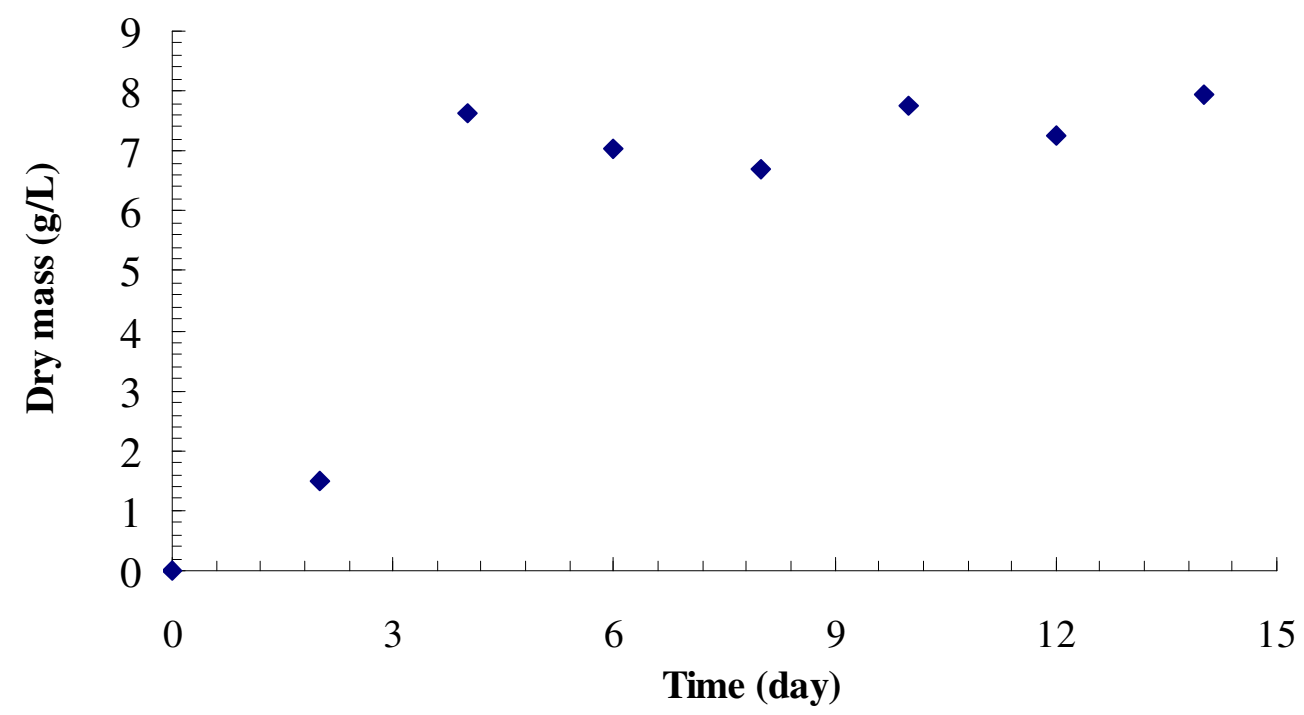

Figure 5 Biomass growth of SMAHS experiment at filtration flux of $24 \mathrm{~L} / \mathrm{m}^{2} . \mathrm{h}$ $(\mathrm{PAC}$ dose $=5 \mathrm{~g} / \mathrm{L}$; aeration rate $=16 \mathrm{~L} / \mathrm{min} ; \mathrm{HRT}=0.21$ day; backwash frequency $=$ 1 hour; backwash duration $=1$ minute; backwash rate $=30 \mathrm{~L} / \mathrm{m}^{2} . \mathrm{h}$ )

The dissolved oxygen variation of the wastewater from the aeration tank was measured to observe the microbial activity on the PAC after different periods of experiment. As shown in Figure 6, the DO concentration changes of $5^{\text {th }}$ and $8^{\text {th }}$ days were $8 \%$ and $7.5 \%$ respectively. The two points responded the two low TOC points. The decrease of TOC removal efficiency was due to the exhausted adsorption of PAC, 
but the high DO concentration indicated that the bacteria cell was in the exponential growth phase. After 9 days, the system maintained constant TOC removal and DO concentration change of the 12-day only reached to $6 \%$.

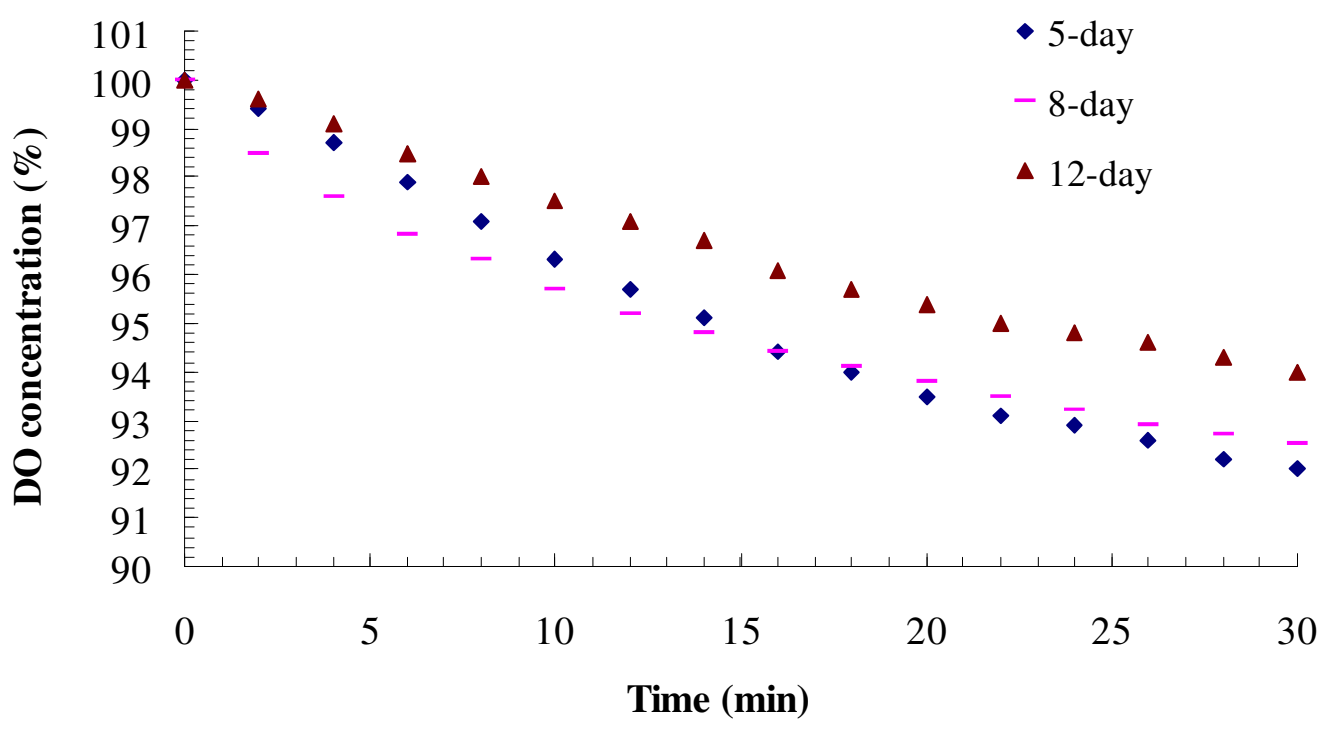

Figure 6 DO concentration variation of SMAHS experiment at filtration flux of 24 $\mathrm{L} / \mathrm{m}^{2} . \mathrm{h}(\mathrm{PAC}$ dose $=5 \mathrm{~g} / \mathrm{L}$; aeration rate $=16 \mathrm{~L} / \mathrm{min} ; \mathrm{HRT}=0.21$ day; backwash frequency $=1$ hour; backwash duration $=1$ minute; backwash rate $=30 \mathrm{~L} / \mathrm{m}^{2} . \mathrm{h}$ )

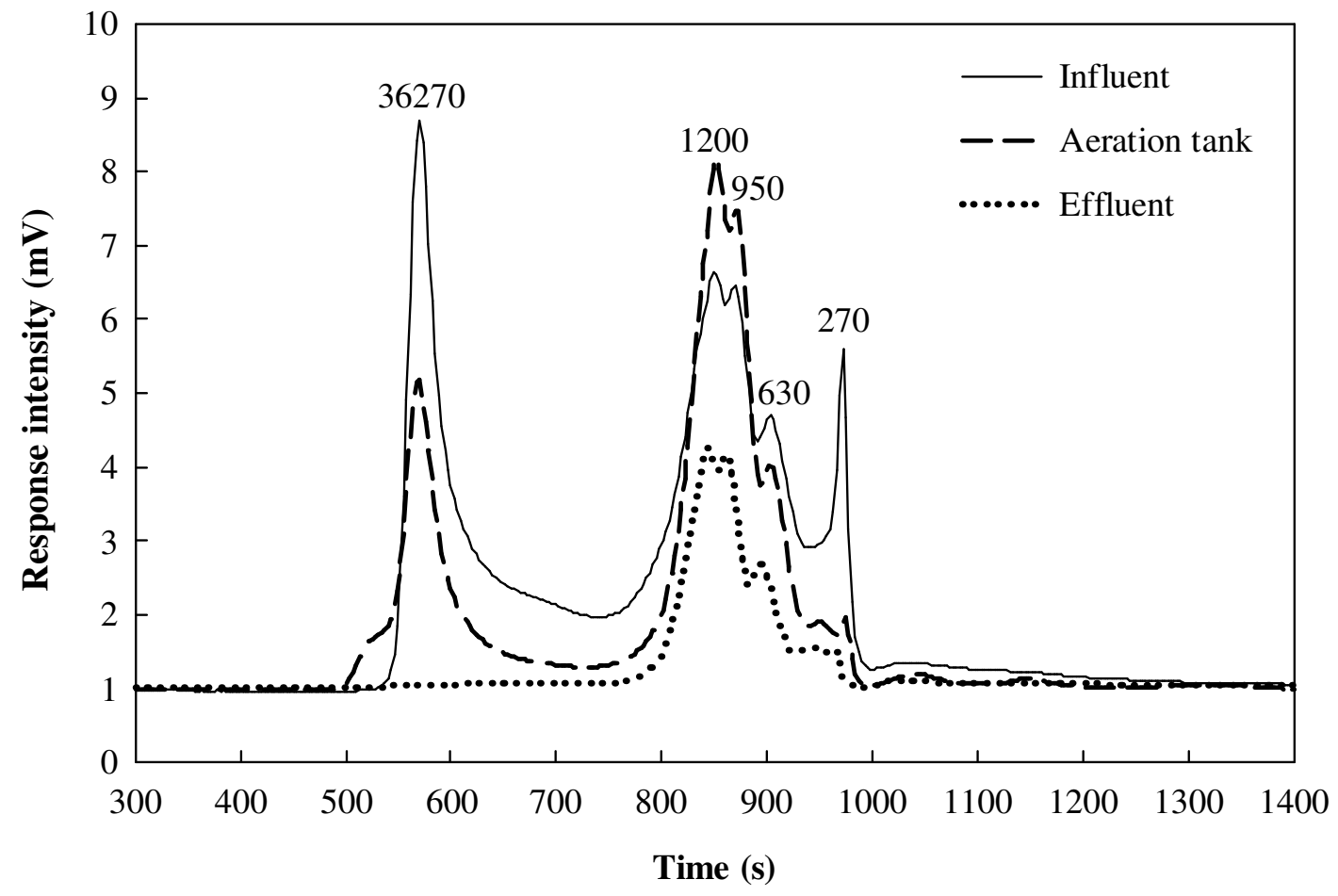

Figure 7 The $14^{\text {th }}$ day MWD of SMAHS experiment at filtration flux of $24 \mathrm{~L} / \mathrm{m}^{2} . \mathrm{h}$ $(\mathrm{PAC}$ dose $=5 \mathrm{~g} / \mathrm{L}$; aeration rate $=16 \mathrm{~L} / \mathrm{min} ; \mathrm{HRT}=0.21$ day; backwash frequency $=$ 1 hour; backwash duration $=1$ minute; backwash rate $=30 \mathrm{~L} / \mathrm{m}^{2} . \mathrm{h}$ ) 
Figure 7 presents the $14^{\text {th }}$ day molecular weight distribution (MWD) of the influent, the wastewater in the aeration tank and the permeate after membrane. In the aeration tank, the small MW fraction of 270 daltons was almost removed, while part of large MW molecules still remained in the tank. In contrast, there was an increase in the fraction of MW molecules about 1000 daltons. This MW represents the carbohydrates which may contain decomposition or metabolic products of the bacteria in the tank. According to the curve of effluent MWD, the large MW (36270 daltons) and the small MW (270-630 daltons) fraction of the synthetic wastewater were almost completely removed by SMAHS. The removal of the small MW molecules is due to the biodegradation of bacteria grown on PAC particles and the reject of biofilm formed on membrane surface.

\subsection{Long term SMAHS experiments with filtration flux of $12 \mathrm{~L} / \mathrm{m}^{2} . h$}

A 55-day long term experiment was carried out at filtration flux of $12 \mathrm{~L} / \mathrm{m}^{2}$.h. The PAC replacement rate was $\left(26 \mathrm{mg} / \mathrm{L}_{\text {(treated water })}\right)$. The other experimental conditions were same as the previous one (filtration flux of $24 \mathrm{~L} / \mathrm{m}^{2} . \mathrm{h}$ ). As expected, the SMAHS had high removal efficiency of organic matter present in the wastewater (Figure 8). The TOC removal efficiency was maintained around $85 \%$ even after 55 days operation and the average TOC removal efficiency was up to $86 \%$. The TMP development during 55 days was only $49 \mathrm{kPa}$ (Figure 9).

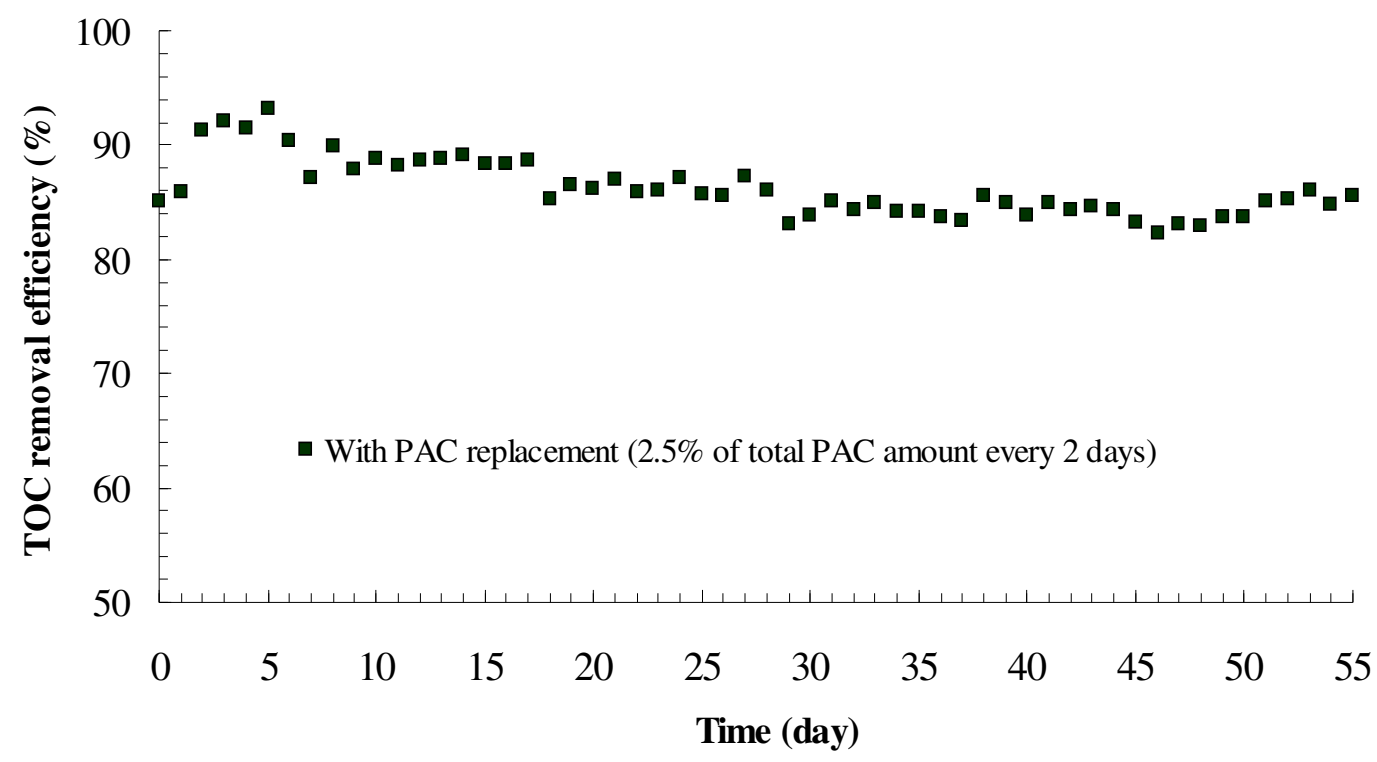

Figure 8 TOC removal efficiency of SMAHS experiment at filtration flux of 12 $\mathrm{L} / \mathrm{m}^{2} . \mathrm{h}($ PAC dose $=5 \mathrm{~g} / \mathrm{L}$; aeration rate $=16 \mathrm{~L} / \mathrm{min} ; \mathrm{HRT}=0.42$ day; backwash frequency $=1$ hour; backwash duration $=1$ minute; backwash rate $=30 \mathrm{~L} / \mathrm{m}^{2} . \mathrm{h}$ ) 


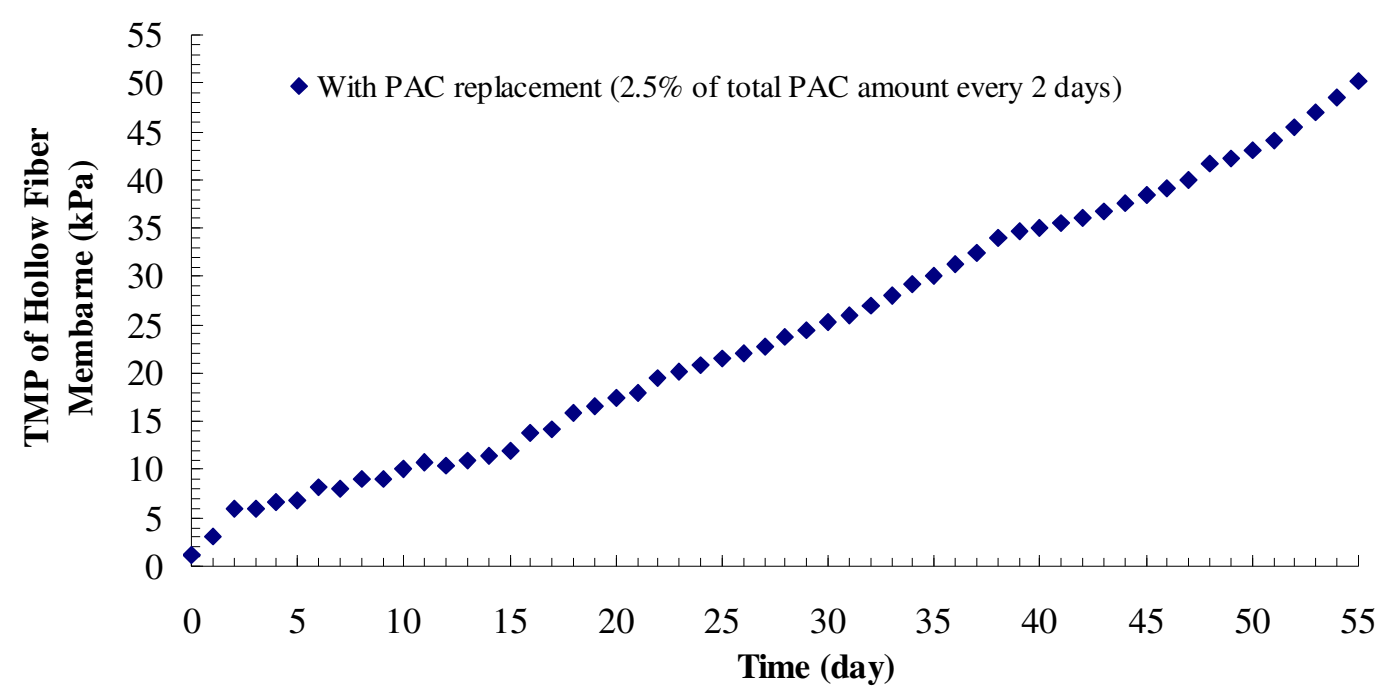

Figure 9 TMP development of SMAHS experiment at filtration flux of $24 \mathrm{~L} / \mathrm{m}^{2} . \mathrm{h}$ $(\mathrm{PAC}$ dose $=5 \mathrm{~g} / \mathrm{L}$; aeration rate $=16 \mathrm{~L} / \mathrm{min} ; \mathrm{HRT}=0.42$ day; backwash frequency $=$ 1 hour; backwash duration $=1$ minute; backwash rate $=30 \mathrm{~L} / \mathrm{m}^{2} . \mathrm{h}$ )

\section{Conclusions}

The submerged membrane adsorption hybrid system (SMAHS) was very effective in removing dissolved organic substances from the synthetic wastewater even with a low dosage of PAC. The pre-adsorption of organics onto PAC helps to reduce the membrane fouling and maintain a consistent permeate flux. The adsorbed organics on the PAC is biodegraded with time, and hence it creates sites for further adsorption of organics on the PAC. The PAC replacement in PAC-MF reactor could stimulate both biological activity and adsorption. With the PAC replacement, the system could keep TOC removal efficiency over $90 \%$ after 15 days run and $85 \%$ after 55 days run. The SMAHS can remove both the large MW (36270 daltons) and the small MW (270-630 daltons) fractions of the synthetic wastewater. However, it only can remove partially the MW molecules of 1000 . The removal of the small MW molecules is due to the biodegradation of bacteria grown on PAC particles and the progressive installation of a biofilm on membrane surface. Therefore, the adsorption-membrane hybrid system has significant potential for long term application in wastewater treatment for reuse.

\section{Acknowledgment}

This research was funded by Australian Research Council (ARC) Discovery grant. The membrane used was provided by Mitsubishi Rayon, Japan through the MOU of the University of Technology, Sydney (UTS) and University of Tokyo and Mitsubishi Rayon. 


\section{References}

[1] C. Visvanathan, R. Ben Aim, and K. Parameshwaran. Membrane separation bioreactors for wastewater treatment, Critical Reviews in Environmental Science and Technology, 30(1) (2000) 1-48.

[2] Yamamoto, K., Hiasa, M., Mahmood, T. and Matsuo, T., Direct solid-liquid separation using hollow fiber membrane in an activated sludge aeration tank, Water Science and Technology, 21(4-5) (1989) 43-54.

[3] Lee, J. C., Kim, J. S., Kang, I. J., Cho, M. H., Park, P. K. and Lee, C. H., Potential and limitations of alum or zeolite addition to improve the performance of a submerged membrane bioreactor, Water Science and Technology, 43(11) (2001) 59-66.

[4] Kim, H. S., Katayama, H., Takizawa, S. and Ohgaki, S., Removal of coliphage Q $\beta$ and organic matter from synthetic secondary effluent by powdered activated carbon-microfiltration (PAC-MF) process, Proceedings of IWA Specialized Conference on Membrane Technology, Israel, (2001) 211-219.

[5] Clark, M. M. and Heneghan, K. S., Ultrafiltration of lake water for potable water production, Desalination, 80(2-3) (1991) 243-249.

[6] C. Campos, B. J. Mariñas, V. L. Snoeyink, I. Baudin and J. M. Laîné, Adsorption of trace organic compounds in CRISTAL $®$ processes, Desalination, 117 (1998) 265-271.

[7] Laine, J. M., Clark, M. M. and Mallevialle J., Ultrafiltration of lake water: effect of pretreatment on the partitioning of organics, THM formation potential, and flux. Journal of AWWA, 82 (1990) 82-87.

[8] Adham, S. S., Snoeyink, V. L., Clark, M. M. and Bersillon, J. L., Predicting and verifying organics removal by PAC in an ultrafiltration system, J. American Water Works Association, 83(12) (1991) 81-91.

[9] G. T. Seo, Y. Suzuki, and S. Ohgaki, Biological powdered activated carbon (BPAC) microfiltration for wastewater reclamation and reuse, Desalination, 106(1-3) (1996) 39-45. 